\title{
Comparative and Parametric Study of Base Isolated Structure
}

\author{
Smita Gupta \\ Department of Structural Engineering, Chhattisgarh Swami Vivekanand Technical University, \\ Newai, Chhattisgarh, 491107, India. \\ E-mail: smtgupta41@gmail.com
}

Received June 29, 2019; received in revised form July 27, 2019; July 29, 2019, Available online July 2019

\begin{abstract}
For the development of better design approach to protect the structures from earthquake damage, base isolation, to reduce the seismic energy impacting on the structure has represented a change of paradigm since it came into the fore. Base isolation technique is most suitable for high rise building, the concept of base isolation is simple, it modifies the response of the building so that the ground can move below the structure without transmitting these motions into the building, seeing the growth of such technology it became necessary to asses the general and seismic response of such structure. The present study focuses on the comparative performance of two frame of different material properties consisting base isolator, which is performed under seismic condition. The base isolation system that is utilized is composed of Rubber isolators. To reach the understanding of this fixed-base and base isolated structure the seismic analysis have performed on two types of structure and the responses are calculated considering different seismic zone. Thus, this paper aimed to compare the responses of simple rcc structure and steel structure due to Indian loadings and seismic zone variations Additionally the structures are analysed and compared using elcentro earthquake data for assessment of responses like interstorey drifts, displacement and base shear.
\end{abstract}

Keywords: Interstorey Drifts; Seismic Response; Fixed-Base and Base Isolated Structure; Design Approach

\section{Introduction}

Base isolation is a technique developed to prevent or minimise damage to building during an earthquake. It has been used in New-zealand as well as India, Japan, Italy and the USA. Base isolation technology can make medium rise masonry or reinforced concrete structures capable of withstanding earthquake, protecting them and their occupants from major damage or injury. The most capable and widely used isolators for medium rise building is lead rubber isolators. it is cost effective also when compared to other isoaters. Thus topic of this thesis is base isolation. Base isolation is a proven technology for the seismic design of structures. The system reduces the likelihood of structural and non-structural damage to a

building subjected to seismic forces. As a result of the use of base isolation, lives and property have been saved. Base isolation technology is used primarily in critical facilities such as hospitals, museums, and emergency response centres, where the benefits of protecting the structure and its property from seismic damage far exceed the cost of implementing the system. However, despite base isolation's proven benefits, the technology is underutilized. Although tall, flexible, and non-critical buildings are not the most ideal candidates for base isolation, they may still achieve an optimal seismic design by using the technology. Therefore, in order to increase the quality and 
prevalence of base isolated structures, there is a need to study the technology's seismic performance enhancements on which the system is infrequently used.

\subsection{Objective and Scope}

This study analyzes a fixed-base and a baseisolated 8-story steel and rcc structure as well for an elcentro earthquake data. Lead rubber bearings are used for the isolation system in the base-isolated structure. The seismic performance of each structure is analyzed and compared for earthquake zone ii and v. 8 ground motions are scaled to each seismic demand level to perform nonlinear time history analyses on both structures. The resulting interstory drifts and displacement values are used to determine the levels of structural and non-structural damage inflicted on each building. In above study the lead rubber isolator is considered and Above study will give an idea about how the placement of isolator will affect the response of the structures with different material properties. Therefore, the different material properties are also considered for better comparison and result

\section{Methodology}

The methodology that followed in this study is given in Figure 1.

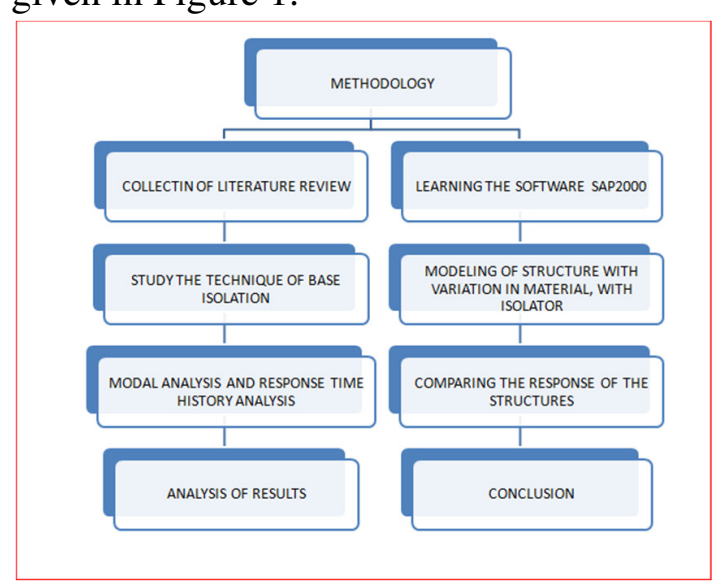

Figure 1 Methodology
Firstly, the collection of literature is done then study about the Base isolation are carried forward, the study was mainly depended upon the different material property of structure, different types of zone and same building height of the structures which are used to take the project further. The software SAP2000 is installed and modelling is done with various parameters later analysis is done and result obtained are compared and concluded.

\section{Modelling}

Structure with fixed based and with base isolator of material property steel and rcc are modelled using the software SAP2000. For designing a new structure, connection details and support conditions shall be made as close to the computational models as possible. For an existing structure evaluation, structures shall be modelled as close to the actual as-built structural conditions as possible. The correct choice of modelling and analysis tools/methods depend on:

a) Importance of the structure

b) Purpose of structural analysis

c) Required level of response accuracy.

Based on this, the models are prepared. It carries a building of $24 \mathrm{~m}$ height.

Beam:- A RCC beam of rectangular shape is considered having the dimension as $0.23 * 0.5$ meters. The grade of concrete used is M-30.

Column:- RCC columns are used of $0.3 * 0.4$ meters and of M-30 grade.

Steel sections: - The grade of steel used is Fe415. And the steel sections used for modeling is ISMB250 and ISMB400 for beams and columns respectively. Slab thickness is taken as 140meters. In this way total 8 models are created having different parameters i.e. RCC fixed based model, RCC model with isolator, 
STEEL fixed based model and STEEL model with base isolator (Fig 3-Fig 5).

During this we took previous data of The 1940 El Centro earthquake (or 1940 Imperial Valley earthquake) occurred at 21:35 Pacific Standard Time on May 18 (05:35 UTC on May 19) in the Imperial Valley in southeastern Southern California near the international border of the United States and Mexico. It had a moment magnitude of 6.9 and a maximum perceived intensity of $\mathrm{X}$ (Extreme) on the Mercalli intensity scale. It was the first major earthquake to be recorded by a strongmotion seismograph located next to a fault rupture. Thus, we took this earth quake data.

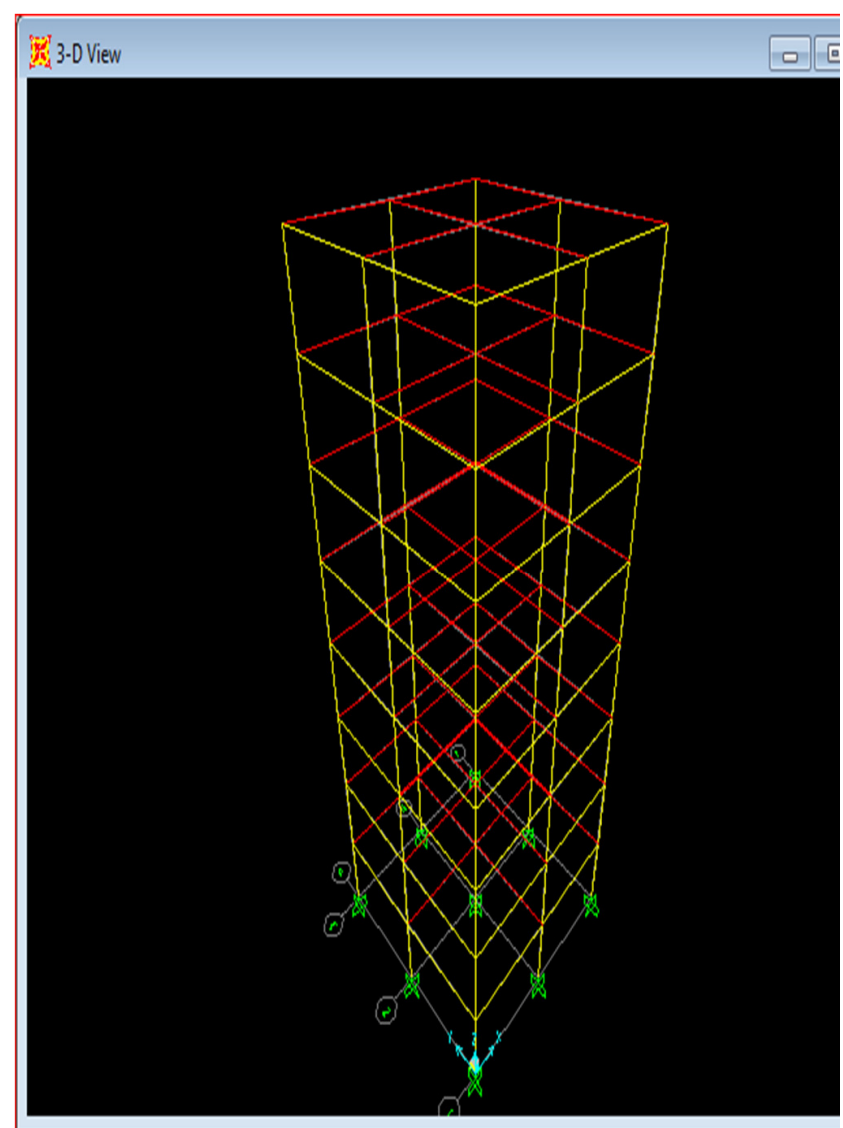

Figure 2 RCC fixed based structure.

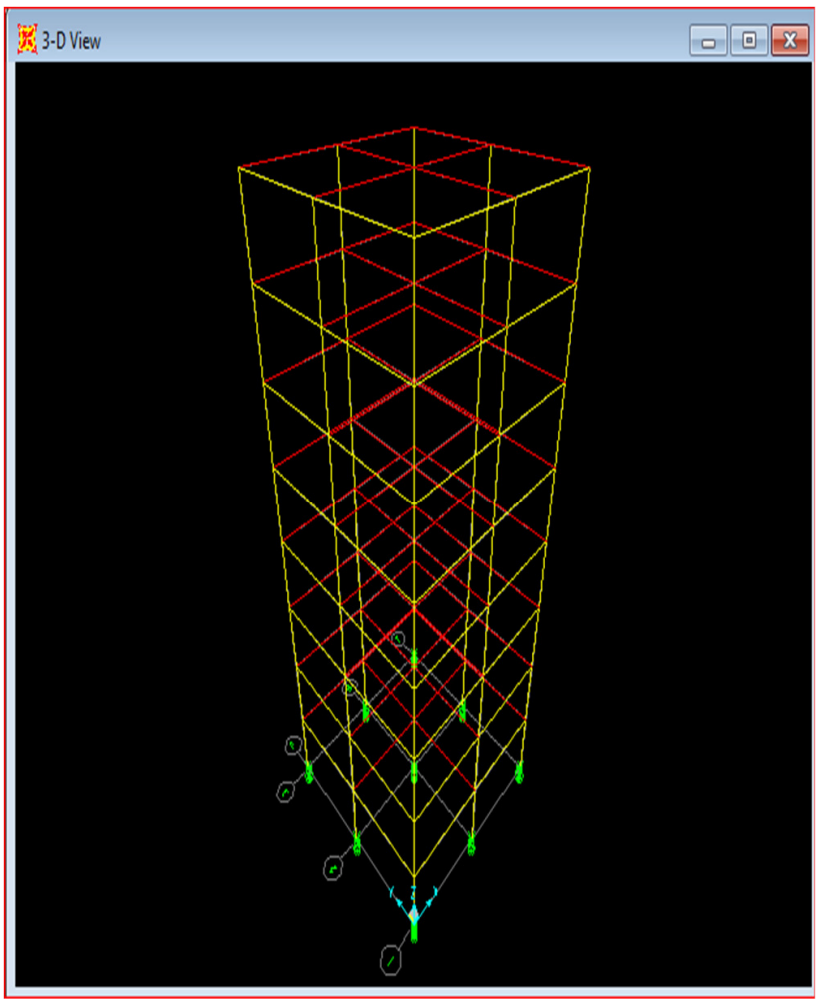

Figure 3 RCC structure with base isolator

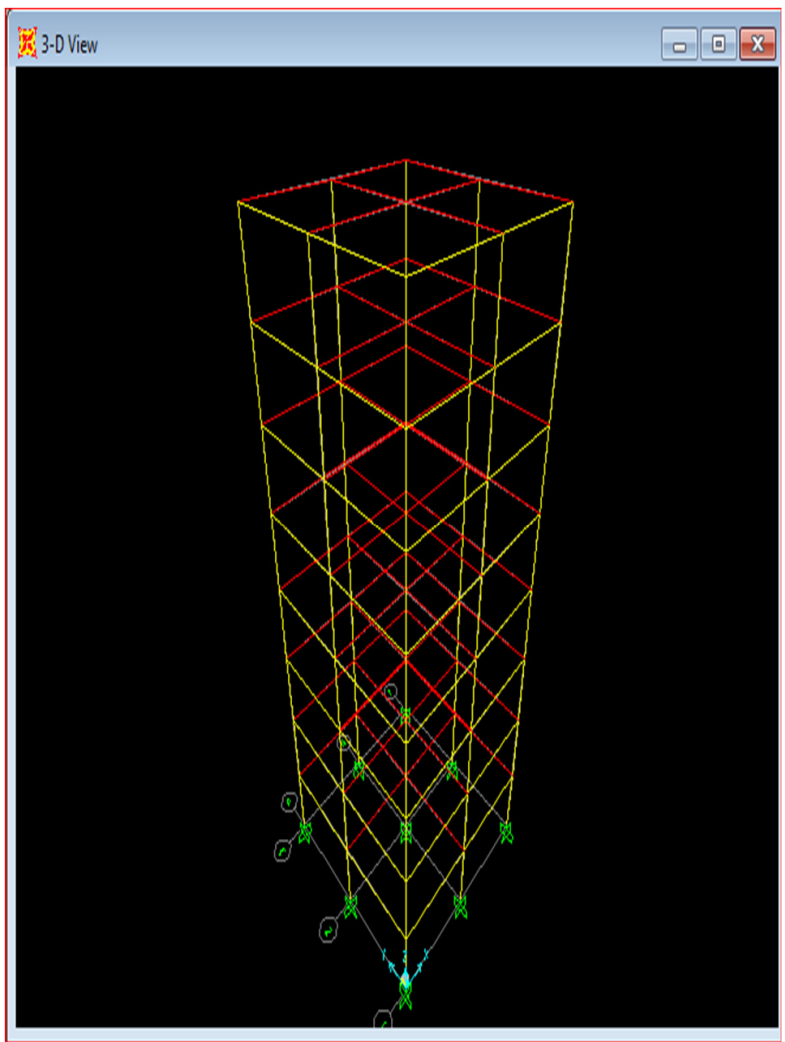

Figure 4 STEEL fixed based structure 


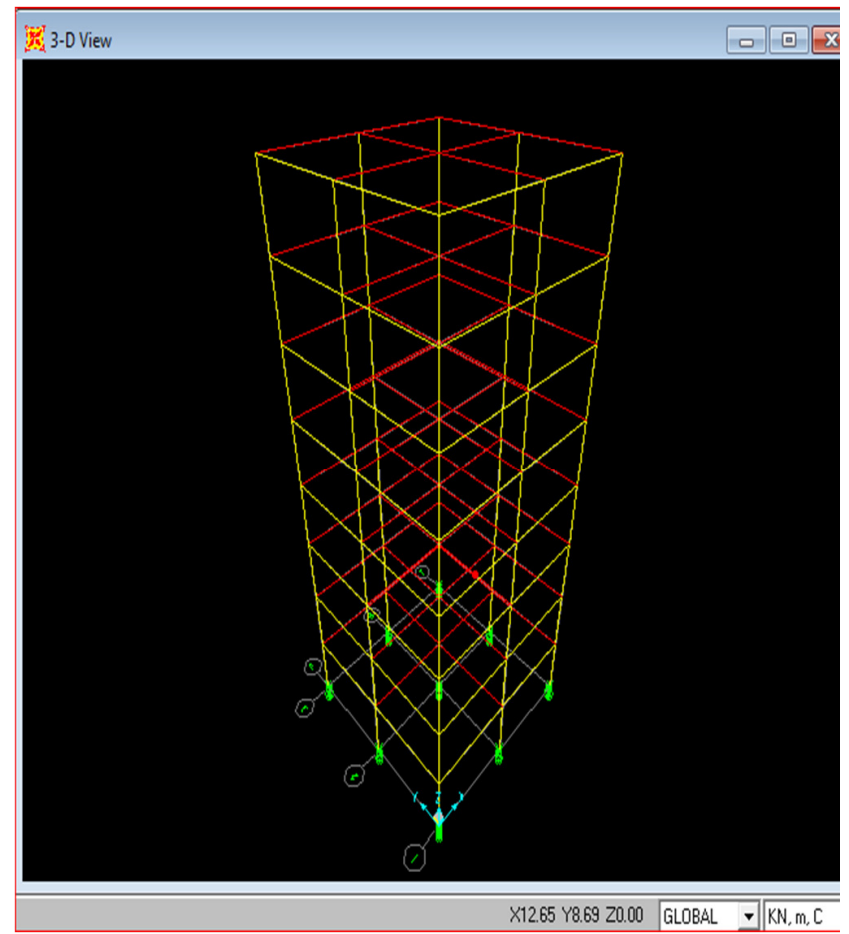

Figure 5 STEEL structure with BI

\subsection{Material Properties}

Different types of materials are used for bridge structural members such as concrete, steel etc. The material properties that are usually used for an elastic analysis are: modulus of elasticity, shear modulus, Poisson's ratio, and the coefficient of thermal expansion, the mass density and the weight density. One should pay attention to the units used for material properties. For linear elastic materials, stresses are linearly proportional to strain $(\sigma=\mathrm{Ec})$ as described by Hooke's Law. The Hooke's Law is applicable for both homogeneous and isotropic materials.

Total 8 models were analyzed. The models are prepared for different materials.

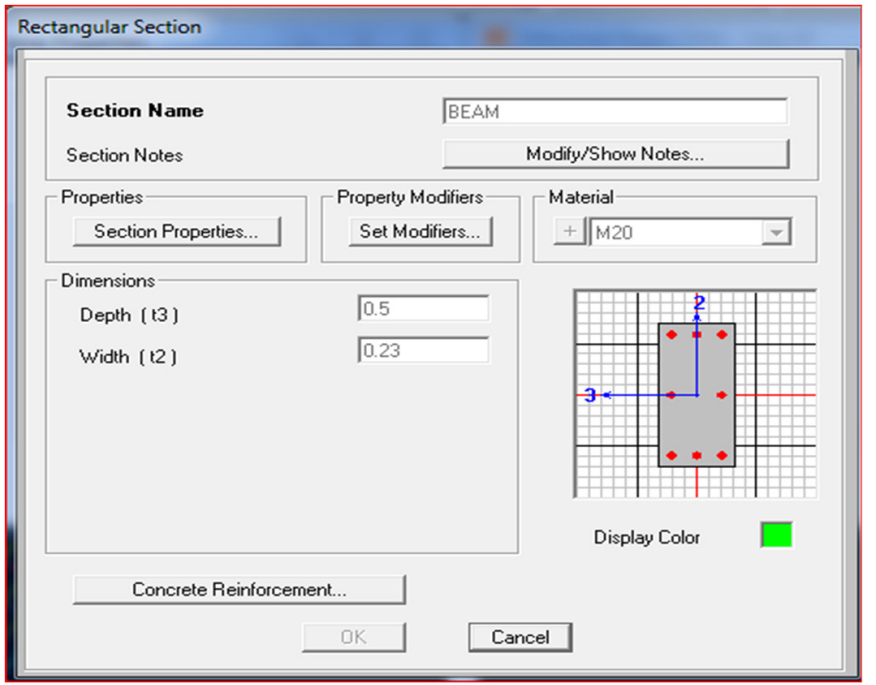

Figure 6 Properties of beam

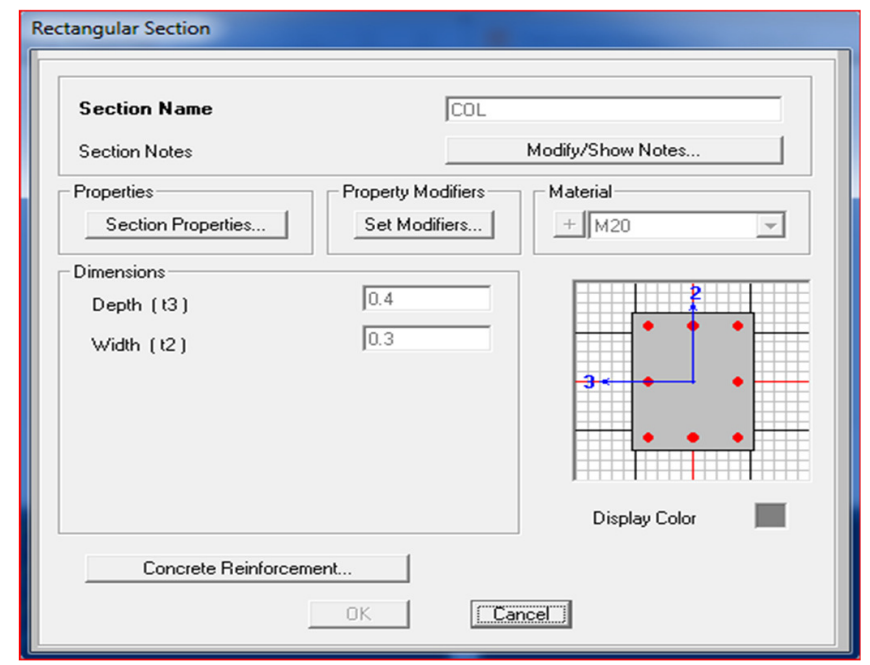

Figure 7 Properties of column

For a simple linear spring, the constitutive law is given as: $F s=k \xi$ where $\zeta$ is the relative extension or compression of the spring, while Fs and $\mathrm{k}$ represent the force in the spring and the spring stiffness, respectively Concrete grade of M30 and steel reinforcement Fe415 is used (Fig 6-Fig. 10). 


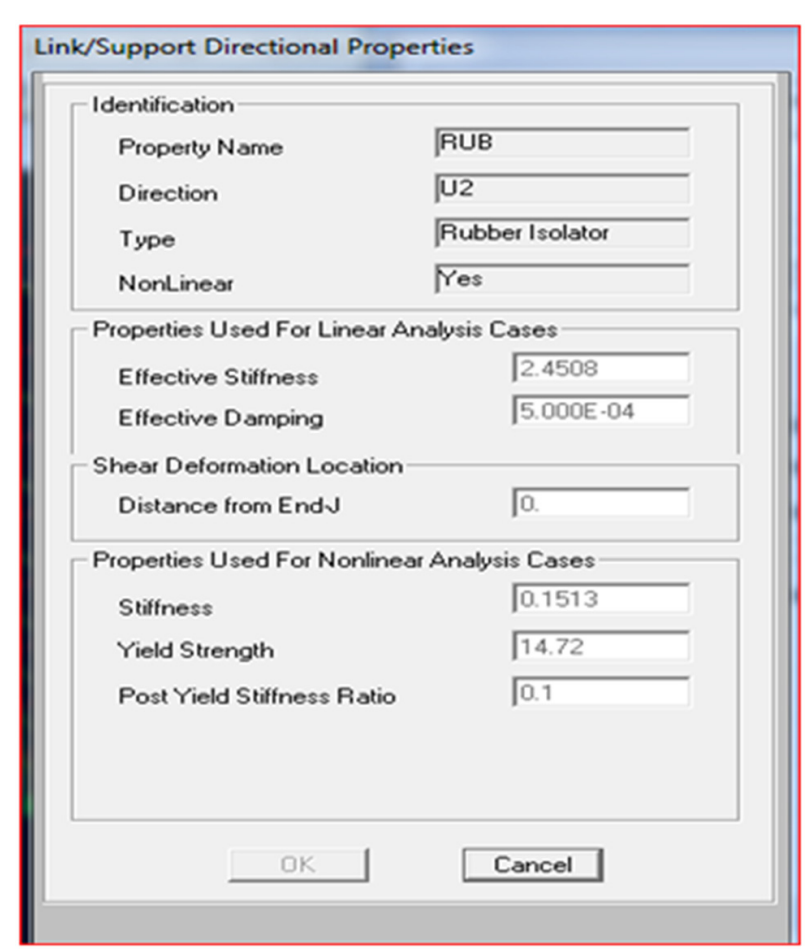

Figure 8 Stiffness of isolators in $\mathbf{u} 2$ direction

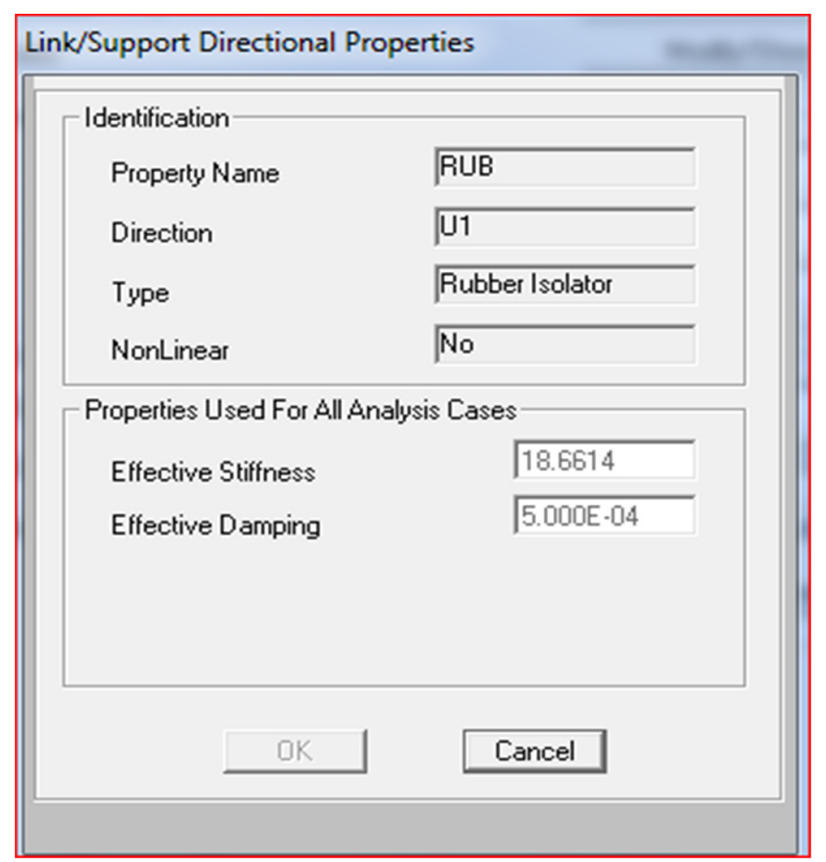

Figure 9 Stiffness of isolators in u1 direction

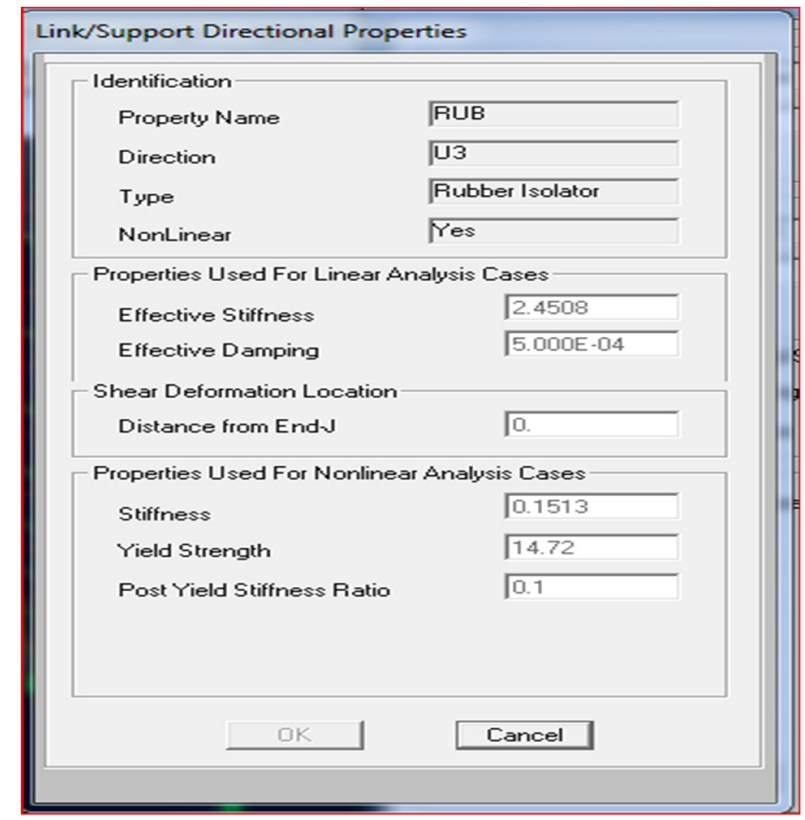

Figure 10 Stiffness of Isolator in U3 Direction

\section{Code Review on Structure Loading}

\subsection{Loading of IS 1893}

Buildings are generally composed of vertical and horizontal structural elements. A complete load path is a basic requirement for all buildings. Seismic forces originating throughout the building, mostly in the heavier mass elements such as diaphragms are delivered throughout the connections to diaphragm, the diaphragm distributes these forces to vertical force resisting system such as shear walls and frames. Through frame these forces are transferred to foundation; and foundation transfers these forces to supporting soil. Interconnecting, members needed to complete the load path is necessary to achieve good seismic performance.

\subsection{Load Combinations Considered}

Since wind is not governing load in this case its combination is not considered. Following combinations are considered for the analysis. After assigning the load cases all the models are analyzed and deformed shape of each model is obtained (Fig.11- Fig. 16). 


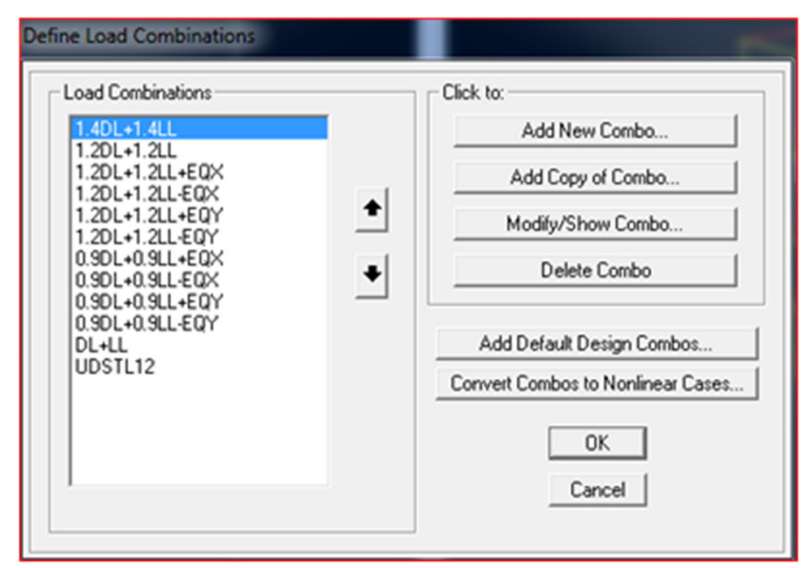

Figure 11 Load Combinations as Per IS1893

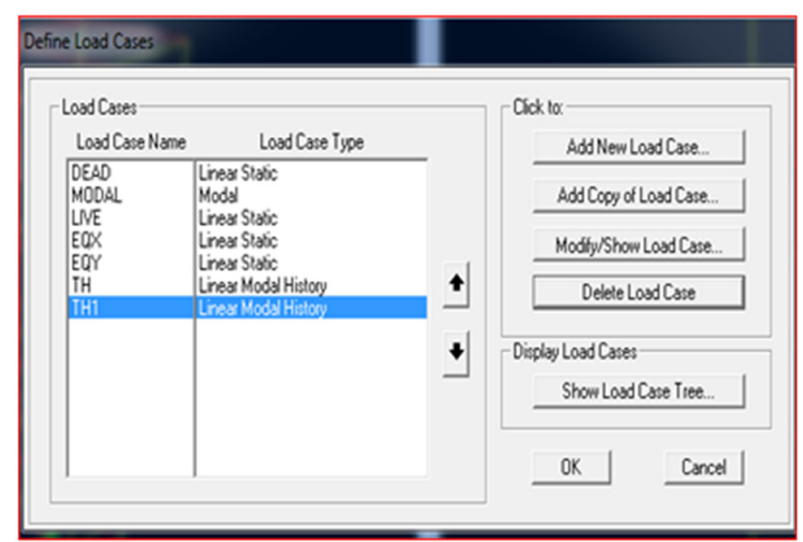

Figure 12 LOAD CASES

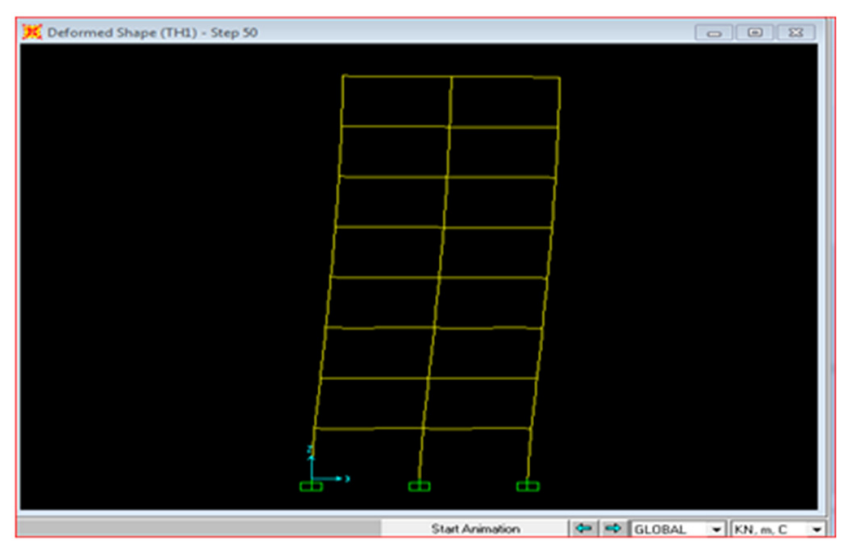

Figure 13 Deformed Shape of RCC Fixed Base Structure.

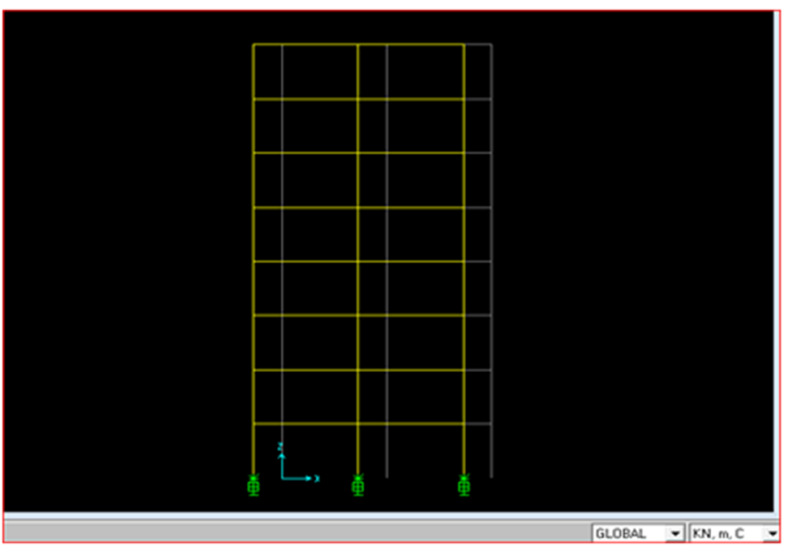

Figure 14 Deformed Shape of RCC Structure With Base Isolator

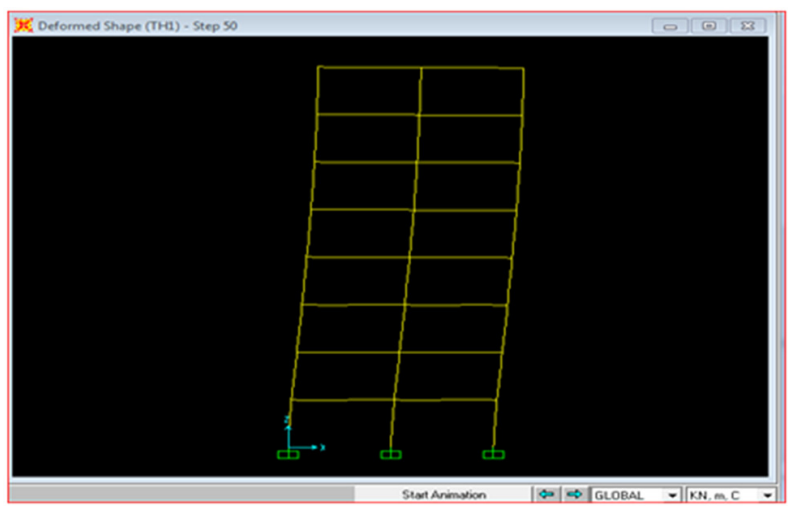

Figure 15 Deformed shape of steel fixed based structure

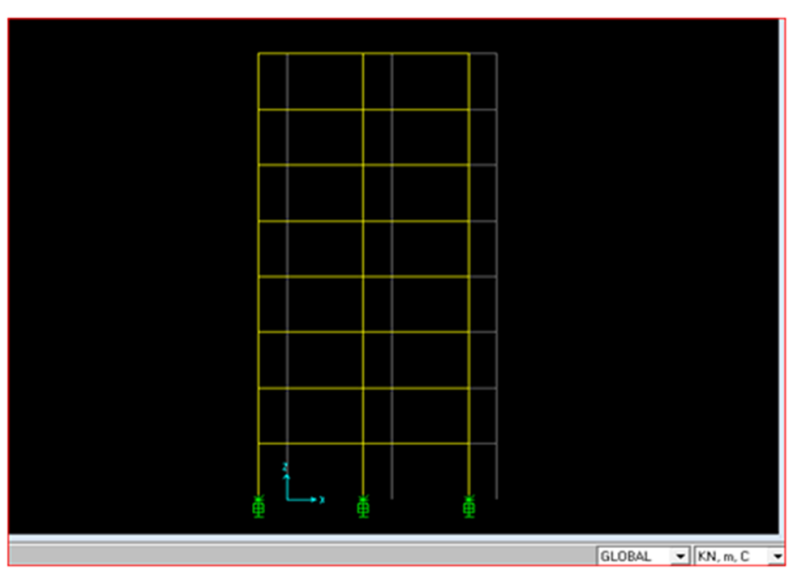

Figure 16 Deformed shape of steel structure with base isolator

\section{Analysis}

The analysis consists of static linear analysis of dead loads. A modal analysis is also conducted 
to calculate the mode shapes and the fundamental frequencies.. Selecting the proper boundary condition has an important role in structural analysis. For a static analysis, it is common to use a simple assumption of supports (i.e. Fixed, pinned, roller) without considering the soil/foundation system stiffness. For specific project, modal analysis and time history analysis are done to calculate the mode shapes, intrstorey drifts and displacement. This will help in compiling data for performing comparative studies on structures with fixed base and base isolation structure situated in different earthquake zones. The seismic motion that reaches a structure on the surface of the earth is influenced by local soil conditions. Low to mid-rise buildings have time period between 0.1 to $1 \mathrm{sec} 19$ range, while taller more flexible buildings have periods between 1 to $5 \mathrm{sec}$ or greater. Harder soils and bed rock transmit short period vibrations (caused by near field earthquake) while filtering out longer period earthquakes (caused by distant earthquakes) whereas softer soils will transmit longer period vibrations.

MODAL ANALYSIS

LINEAR STATIC ANALYSIS

MOVING LOAD ANALYSIS

TIME HISTORY ANALYSIS.

\section{Results and discussion}

1) It has been seen that the RCC displacement in zone $\mathrm{V}$ is $32.6 \%$ more than zone II under fixed base condition while model with isolator displacement in zone II is $158 \%$ more than zone V (Table 7.1-7.2).

This can be seen from Table 7.3-7.4 that as isolator works more effectively in zone II as compare to zone V. As impact is more in zone $\mathrm{V}$. Thus, isolator displaces less in zone V.
2) For steel displacement in Zone $\mathrm{V}$ is $39.4 \%$ more than zone II under fixed base. Also, it should be noted that steel is more ductile material. That is why it will perform better even in seismic loading. It can be seen in below data. The model with isolator displacement in Zone II is $34.9 \%$ more than zone $\mathrm{V}$.

Thus, as compared to RCC the steel building with isolator perform better because it displaces more with isolator in zone $\mathrm{V}$ which is Earthquake highest impact zone. Also, the difference in displacement between zone II and $\mathrm{V}$ is very less in steel which shows its effectiveness in building structure.

3) The plot between no. of storeys and their drift for RCC structures with fix base zone V shows 5.5 times higher drift at ground level as compared to zone II. Also with increase in height it reduces which shows lesser drift at higher level.

Also, if we analyse the same plot for steel structure with fixed base zone $\mathrm{V}$ shows 5 times higher drift at ground level as compared to zone II. This shows steel structures act 0.5 times better when we talk about drift values.

4) The plot between no. of storey and their drift for Steel structures with isolators in zone $\mathrm{V}$ is $34.2 \%$ more than zone II and gradually with increase in no. of storey the drift values acts stable which shows that isolators acts efficiently.

Also in case of RCC structures the zone $\mathrm{V}$ is $150 \%$ more than zone II and gradually with increase in storey the drift values acts stable. it can be seen that in steel drift variation is less which shows that the structure acts effectively in zone $\mathrm{V}$ as compared to RCC structures. 
5) It is also seen from the base shear vs time period curve that the max base shear value for RCC is $189 \%$ higher than Steel structures. This shows the base shear is considerably reduced with the help of isolation technique.

6) It can be seen in Fig-17-20 of zone II graphs of $\mathrm{RCC} /$ Steel that how the displacement gradually increases with the no of storey while if you see the $1200 / 1250 \mathrm{~mm}$ displacement respectively of BI system in the same plot we can clearly say that how the use of base isolation technique increases the displacement value at ground level thus increasing the time period of the building. as we know time period is inversely proportional to frequency we can see the frequency is sufficiently reduced with the help of base isolation technique.

7) The Fig. 21-24 of zone $V$ graphs of $\mathrm{RCC} /$ Steel shows reduction in the displacement value 467/1200 respectively as compare to zone II the displacement of RCC in zone $\mathrm{V}$ is drastically reduced while that of is steel is slightly reduced. This shows that how the base isolation system give better results with steel even in zone $\mathrm{V}$. While with the reduction of displacement the time period is decreased in zone V of RCC.

Thus, we can predict from above discussion that how steel structure performs better with the earthquake prone areas and also hoe the installation of base isolation system considerably increases the effectiveness of the building by deducing the frequency (Fig. 2526).

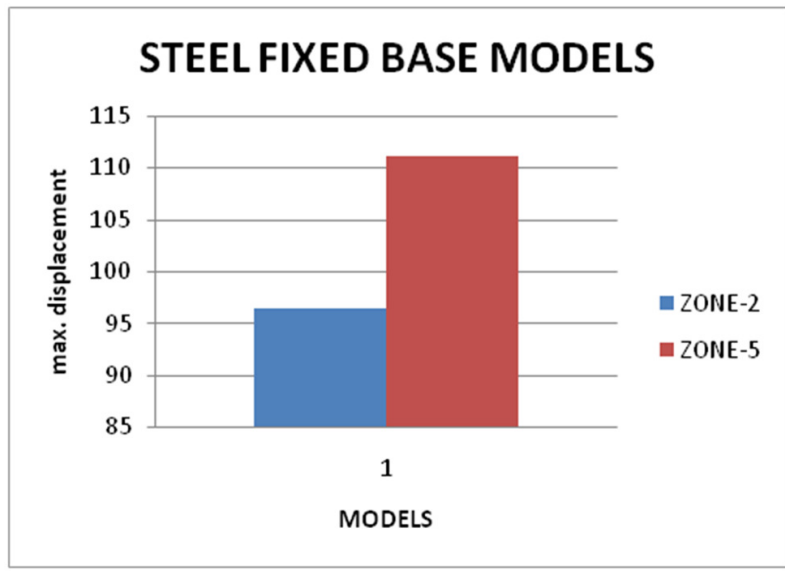

Figure 17 Maximum displacement for steel fixed based structure

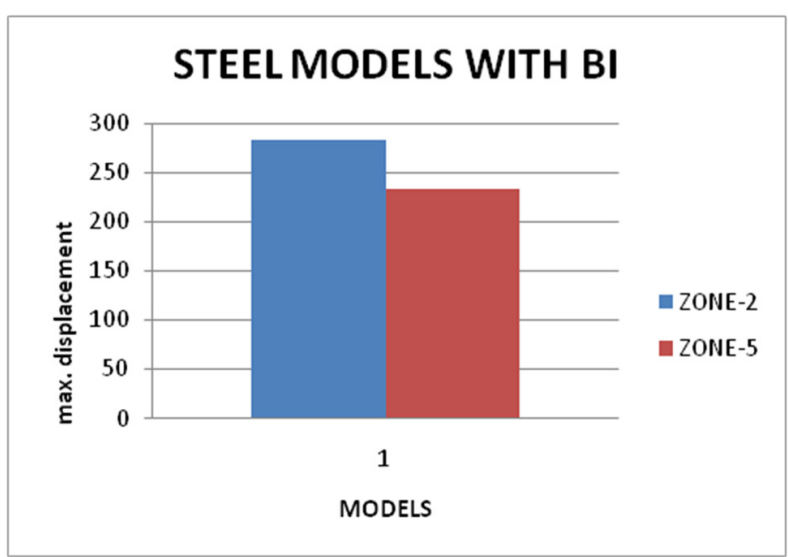

Figure 18 Maximum Displacement for steel structures with BI system

Table 7.1 Seismic zones vs. displacement of steel structures

\begin{tabular}{|l|l|l|l|l|}
\hline Storey & \multicolumn{3}{|l|}{\begin{tabular}{l} 
Displacement of \\
\cline { 2 - 5 }
\end{tabular}} & \multicolumn{2}{l|}{$\begin{array}{l}\text { Displacement } \\
\text { STEEL FIXED }\end{array}$} & \multicolumn{2}{l|}{$\begin{array}{l}\text { STEEL WITH BI } \\
\text { System (mm) }\end{array}$} \\
\cline { 2 - 5 } & ZOSED (mm) & ZONE-V & ZONE-II & ZONE-V \\
\hline 8 & 96.5346 & 111.1542 & 282.793 & 232.8614 \\
\hline 7 & 87.5292 & 97.5672 & 281.951 & 230.351 \\
\hline 6 & 78.5346 & 88.5726 & 281.928 & 230.331 \\
\hline 5 & 67.2752 & 77.3132 & 281.899 & 230.253 \\
\hline 4 & 54.7238 & 64.7618 & 281.865 & 230.179 \\
\hline 3 & 41.6822 & 51.7202 & 281.824 & 230.089 \\
\hline 2 & 29.2334 & 39.298 & 281.778 & 230.84 \\
\hline 1 & 8.9756 & 19.348 & 281.727 & 229.865 \\
\hline 0 & 0 & 0 & 0 & 0 \\
\hline
\end{tabular}




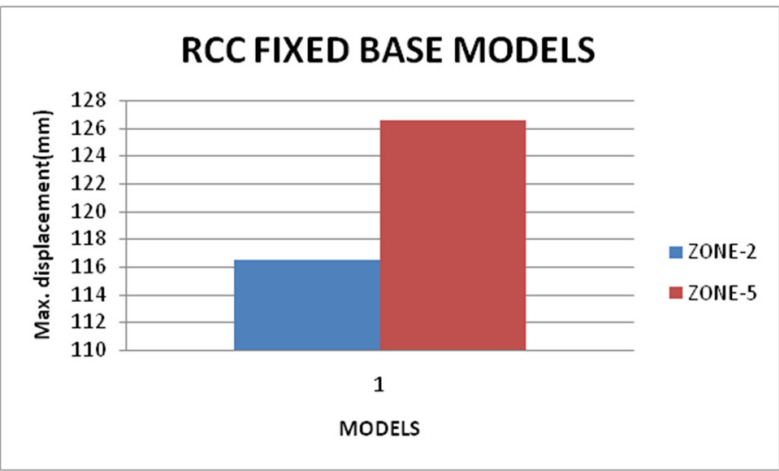

Figure 19 Maximum displacement of RCC fixed based model

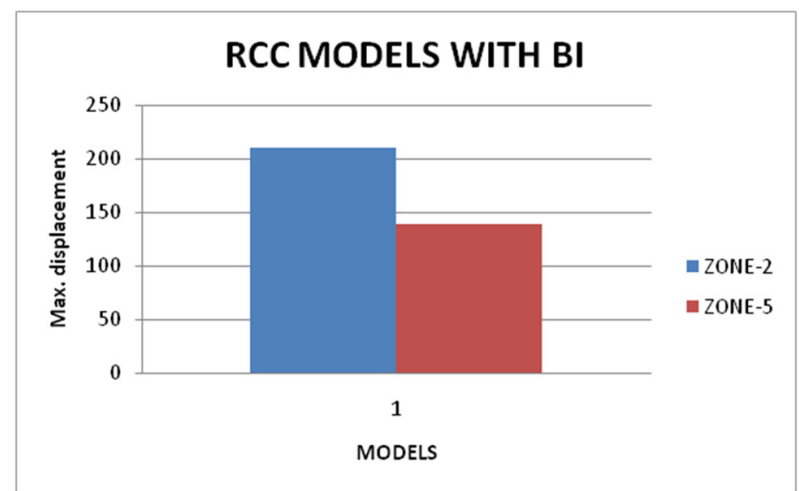

Figure 20 Maximum displacement of RCC structre with BI system

Table 7.2 Seismic zones vs displacement for RCC structures

\begin{tabular}{|l|l|l|l|l|}
\hline \multirow{2}{*}{ Storey } & \multicolumn{2}{|l|}{$\begin{array}{l}\text { Displacement of RCC } \\
\text { FIXED BASED }(\mathrm{mm})\end{array}$} & \multicolumn{2}{l|}{$\begin{array}{l}\text { Displacement of RCC } \\
\text { WITH BI system }(\mathrm{mm})\end{array}$} \\
\cline { 2 - 5 } & ZONE-II & ZONE-V & ZONE-II & ZONE-V \\
\hline 8 & 116.5004 & 126.5042 & 209.7007 & 139.7076 \\
\hline 7 & 110.0708 & 120.0784 & 208.956 & 138.956 \\
\hline 6 & 99.8526 & 109.8602 & 208.867 & 138.867 \\
\hline 5 & 85.7242 & 95.7318 & 208.754 & 138.754 \\
\hline 4 & 61.636 & 79.1638 & 208.618 & 138.618 \\
\hline 3 & 50.6312 & 60.6388 & 208.462 & 138.461 \\
\hline 2 & 31.0688 & 41.0764 & 208.284 & 138.484 \\
\hline 1 & 12.2816 & 22.2892 & 208.091 & 138.091 \\
\hline 0 & 0 & 0 & 0 & 0 \\
\hline
\end{tabular}

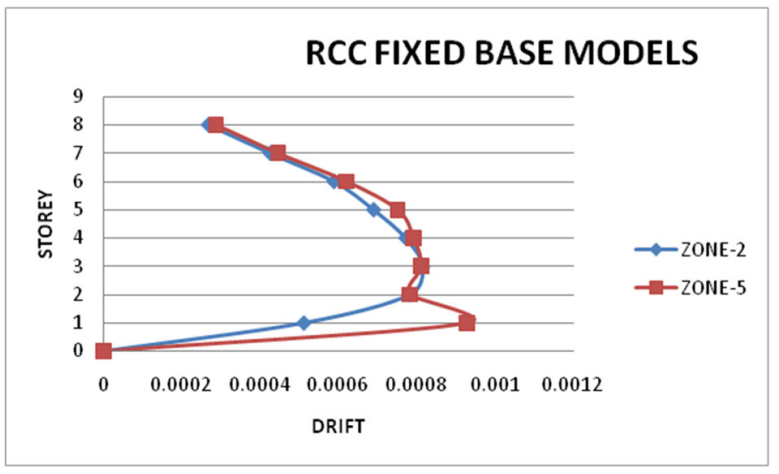

Figure 21 Interstorey drift of RCC fixed base structure

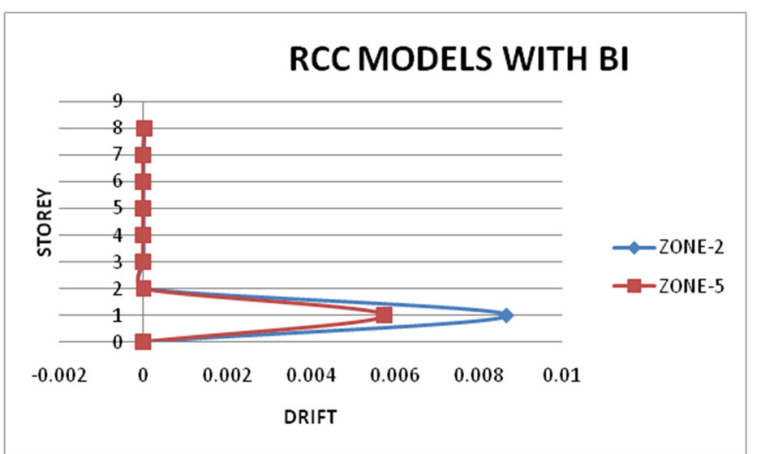

Figure 22 Interstorey drift of RCC structure with BI system

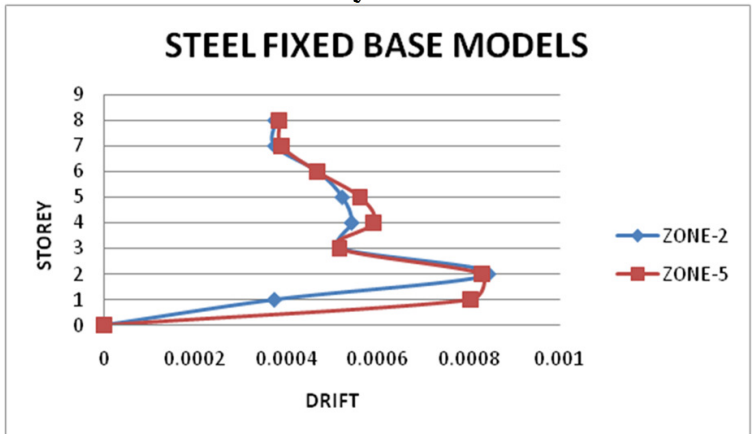

Figure 23 Interstorey drift of STEEL fixed base structure.

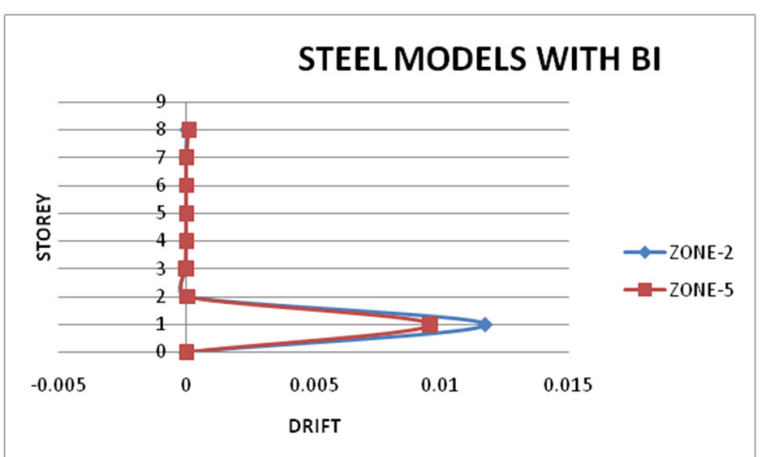

Figure 24 Interstorey drift of STEEL structure with BI system 


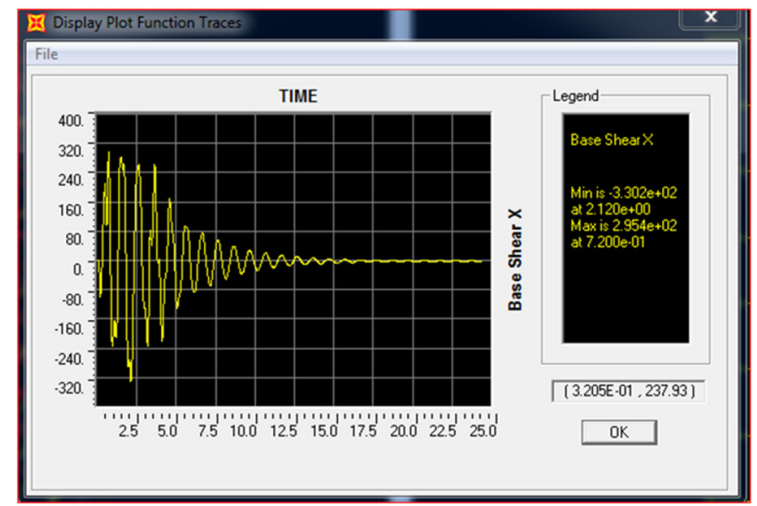

Figure 25 Max base shear for RCC system.

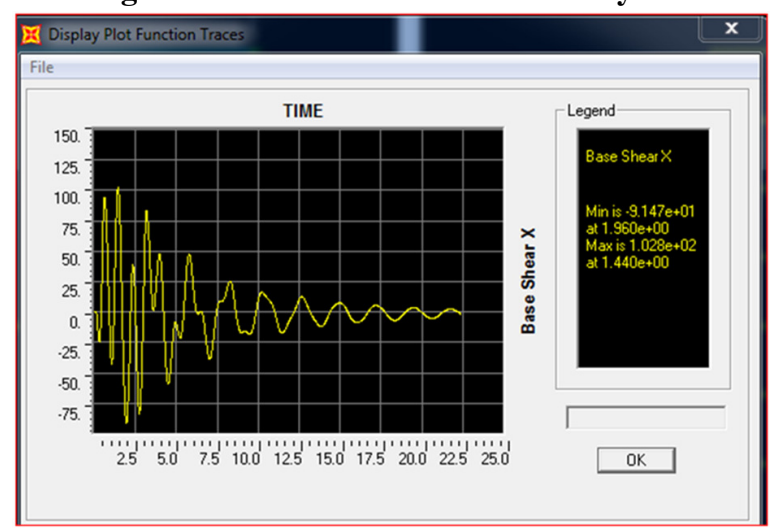

Figure 26 Max base shear curve for steel system

Table 7.3 Seismic zones vs Drift for RCC structures

\begin{tabular}{|l|l|l|l|l|}
\hline \multirow{2}{*}{$\begin{array}{l}\text { Stor } \\
\text { ey }\end{array}$} & \multicolumn{2}{|l|}{$\begin{array}{l}\text { Drift of RCC FIXED } \\
\text { BASED }(\mathrm{mm})\end{array}$} & \multicolumn{2}{l|}{$\begin{array}{l}\text { Drift of RCC WITH BI } \\
\text { system }(\mathrm{mm})\end{array}$} \\
\cline { 2 - 5 } & ZONE-II & ZONE-V & ZONE-II & ZONE-V \\
\hline 8 & 0.000268 & 0.000288 & $3.1 \mathrm{E}-05$ & $3.1315 \mathrm{E}-05$ \\
\hline 7 & 0.000426 & 0.000446 & $3.71 \mathrm{E}-06$ & $3.70833 \mathrm{E}-06$ \\
\hline 6 & 0.000589 & 0.000621 & $4.71 \mathrm{E}-06$ & $4.70833 \mathrm{E}-06$ \\
\hline 5 & 0.000690 & 0.000751 & $5.67 \mathrm{E}-06$ & $5.66667 \mathrm{E}-06$ \\
\hline 4 & 0.000772 & 0.000792 & $6.5 \mathrm{E}-06$ & $5.66667 \mathrm{E}-06$ \\
\hline 3 & 0.000815 & 0.000811 & $7.42 \mathrm{E}-06$ & $-9.5833 \mathrm{E}-07$ \\
\hline 2 & 0.000783 & 0.000783 & $8.04 \mathrm{E}-06$ & 0.000016375 \\
\hline 1 & 0.000512 & 0.000929 & 0.00867 & 0.005753792 \\
\hline
\end{tabular}

Table 7.4 Seismic zones vs Drift for Steel structure
\begin{tabular}{|l|l|l|l|l|}
\hline \multirow{2}{*}{$\begin{array}{l}\text { stor } \\
\text { ey }\end{array}$} & \multicolumn{2}{l}{$\begin{array}{l}\text { Drift of RCC FIXED } \\
\text { BASED }(\mathrm{mm})\end{array}$} & $\begin{array}{l}\text { Drift of RCC WITH BI } \\
\text { system }(\mathrm{mm})\end{array}$ \\
\cline { 2 - 6 } & ZONE-II & ZONE-V & ZONE-II & ZONE-V \\
\hline 8 & 0.000375 & 0.000385 & $3.50817 \mathrm{E}-05$ & 0.000105 \\
\hline 7 & 0.000375 & 0.000391 & $9.58333 \mathrm{E}-07$ & $8.33 \mathrm{E}-07$ \\
\hline 6 & 0.000469 & 0.000469 & $1.20833 \mathrm{E}-06$ & $3.25 \mathrm{E}-06$ \\
\hline 5 & 0.000523 & 0.000563 & $1.41667 \mathrm{E}-06$ & $3.08 \mathrm{E}-06$ \\
\hline 4 & 0.000543 & 0.000593 & $1.70833 \mathrm{E}-06$ & $3.75 \mathrm{E}-06$ \\
\hline 3 & 0.000519 & 0.000518 & $1.91667 \mathrm{E}-06$ & $-3.1 \mathrm{E}-05$ \\
\hline 2 & 0.000844 & 0.000831 & $2.125 \mathrm{E}-06$ & $4.06 \mathrm{E}-05$ \\
\hline 1 & 0.000374 & 0.000806 & 0.011738625 & 0.009578 \\
\hline
\end{tabular}

\section{Summary and conclusion}

Structural buildings of two materials i.e. RCC and Steel are analyzed. The support condition are fixed and with isolators. Both the cases have been checked for different earthquake zones. The data analyzed with nodal and time history . The obtained results are under different parameters such as storey drift, max displacement, base shear and time period.

From the result and discussion we can predict from that how steel structure performs better with the earthquake prone areas and also hoe the installation of base isolation system considerably increases the effectiveness of the building by deducing the frequency

\section{Conflict of interest}

The authors declare no conflict of interest.

\section{References}

[1] Kalantari, S.M., Naderpour, H. and Vaez, S.H., 2008. Investigation of Base-isolator type selection on seismic behavior of structures including story drifts and plastic hinge formation. In The 14th World Conference on Earthquake Engineering, Beijing, China..

[2] Mazza, Fabio, and Alfonso Vulcano. "BaseIsolation techniques for the seismic protection of RC Framed Structures subjected to near-fault ground motions." 13th WCEE. 2004.

[3] Matsagar, V. A., \& Jangid, R. S. (2003). Seismic response of base-isolated structures during impact with adjacent structures. Engineering Structures, 25(10), 1311-1323.

[4] Palermo, M., Ricci, I., Gagliardi, S., Silvestri, S., Trombetti, T., \& Gasparini, G. (2014). Multiperformance seismic design through an enhanced first-storey isolation system. Engineering structures, 59, 495-506. 
[5] Providakis, C. P. (2008). Pushover analysis of base-isolated steel-concrete composite structures under near-fault excitations. Soil dynamics and earthquake Engineering, 28(4), 293-304..

[6] Su, L., Ahmadi, G. and Tadjbakhsh, I.G., 1990. Responses of base-isolated shear beam structures to random excitations. Probabilistic Engineering Mechanics, 5(1), pp.35-46.

[7] Kilar, Vojko, et al. (2011) "Seismic analysis of an asymmetric fixed base and base-isolated highrack steel structure." Engineering Structures 33.12: 3471-3482.

[8] IS 456-2000, Guidelines for Indian Standard Plain and Reinforcing concrete code of practices.

[9] IS 1893: 2002 Criteria For Earthquake Resistant Design of Structures.

[10] IS: 800 - 2007 Indian Standard General Construction In Steel - Code of Practice. 